\title{
Representações dos modelos clássicos militares no rei medieval português
}

\section{Classics military models' representations into the portuguese medieval king}

Resumo: Perante o tema geral que nos foi proposto - «representações do masculino» - o assunto do nosso trabalho constitui um refúgio, uma espécie de santuário. Assim, entrincheiramo-nos na rei militaris, exclusiva do gênero masculino e na representação do rei como paradigma. Rei e reino formam a mesma matéria, construída pela força das armas e garantida na suprema representação dos poderes régios. A imagem do rei medieval português, plena de futuras potencialidades, contém em si o modelo e a substância afirmada na longa evolução das monarquias da Antiguidade.

Palavras-chave: Rei - representações - guerra - poder - gênero

Abstract: Given the general theme that has been proposed - «representations of the male gender» the subject of our paper is as a refuge, a sanctuary. Our perspective is to work from the concept of rei militaris, exclusive of the male gender, and from the representation of the king as a paradigm. King and kingdom form the same matter, built by the force of arms and guaranteed by the ultimate representation of royal power. The image of the medieval Portuguese king, full of future potential, contains within itself the model and substance stated in the long evolution from Ancient monarchies and empires.

Keywords: King - representations - war - kingship - gender

Perante o tema geral que nos foi proposto - «representações do masculino» - o tema do nosso trabalho constitui um refúgio, uma espécie de santuário. $\mathrm{Na}$ verdade, a sugestão parecia apontar para um estudo no âmbito da História do Gênero, área em que nenhum de nós trabalha e para a qual se tem pouca sensibilidade com vista a estabelecer qualquer inquérito. Assim,

\footnotetext{
* Professora Auxiliar com Agregação da Faculdade de Letras da Universidade de Lisboa e investigadora do Centro de His tória da Faculdade de Letras da Universidade de Lisboa. margaridagarcezventura@gmail.com

* Professor Auxiliar da Faculdade de Letras da Universidade de Lisboa e investigador do Centro de História da Faculdade de Letras da Universidade de Lisboa. zvarandas@gmail.com

* Mestranda em His tória da Arte na Faculdade de Letras da Universidade de Lisboa e bolseira de investigação do Centro de História da Faculdade de Letras da Universidade de Lisboa. inesmeiraaraujo@gmail.com
} 
entrincheiramo-nos na rei militaris (para usar a expressão de Vegécio (VEGÉCIO,2009)), exclusiva do gênero masculino. Longe de nós, entrar aqui na querela entre aptidões naturais ou aptidões adquiridas no que concerne às funções masculinas e femininas; ou mesmo tentar cruzar alterações de mentalidade com novas tecnologias bélicas. Fiquemos pelos fatos: a guerra na Antiguidade e na Idade Média é praticada por homens; ${ }^{1}$ mas, as mulheres, quando mencionadas, o são como elemento de perturbação ou de pecado. ${ }^{2}$ No Mundo Antigo, a exceção situa-se no plano do mito ou da lenda (as Amazonas); na Idade Média, Joana d'Arc parece quebrar a regra. Todavia, é de notar que, se é certo que uma das acusações constantes do seu processo era vestir-se e comportar-se como um homem de armas, traindo a lei natural e divina (como consta no Auto de Acusação), a própria

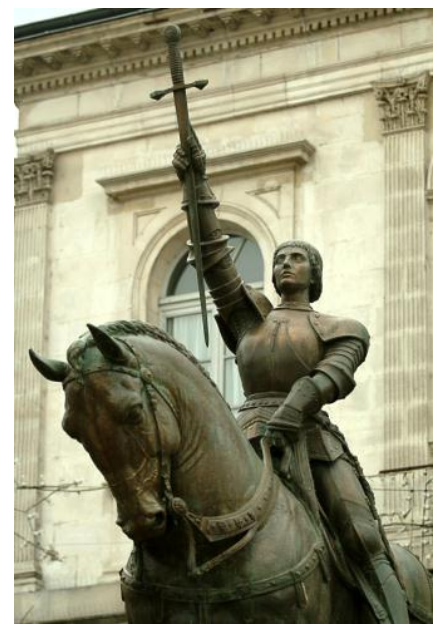
acusada anulou, por essa mesma forma, a exceção: foi como homem que Joana combateu. ${ }^{3}$

Embora geralmente apenas se aborde a recuperação do mundo clássico no período do Renascimento, sabemos que durante a Idade Média o contato com a Antiguidade nunca foi esquecido. Em termos literários, as suas histórias mantiveram-se nas bibliotecas, foram copiadas, traduzidas, lidas e relidas, tal como as obras de arte (ainda que muitas delas tenham sido destruídas pela iconoclastia) não deixaram de influenciar o pensamento estético medieval. É disso exemplo o chamado «Renascimento carolíngio», que teve como uma das suas premissas a conservação e cópia de variados manuscritos antigos, como os grandes autores clássicos. Virgilio, Ovídio, Horácio, entre outros, não deixaram de ser estudados e comentados, tal como faziam sucesso Romance de Tebas, de Troia ou de Eneias (DELUMEAU, 1984, p.75-79). No Portugal medievo, segundo os estudos que possuímos sobre as bibliotecas dos monarcas D. Duarte, o infante D. Pedro e D. Afonso V, sabemos da existência dos seguintes autores e obras da cultura greco-romana: Aristóteles, Valério Máximo, Sêneca comentado, Cícero, Vegécio, Tito Lívio, Júlio César, Historia de Troya (em aragonês), Sonho de Cipião, Suetônio, a Vida de César, Túlio, Plutarco, Virgílio, Plínio, Tácito, Ovídio, Commentarios de Cesar, Homero, entre outros. (BRAGA, 2005, p. 358-362). Temos, também, de ter em conta que no período medieval as histórias e escritos antigos são moralizados ou adaptados à realidade da época, sendo as figuras míticas, muitas vezes, transformadas em cavaleiros de arnês completo e representadas segundo os cânones coevos. Na Baixa Idade Média observamos a recuperação do ideal antigo, mas em um paradigma social muito diferente e claramente marcado 
pelo pensamento cristão, transformando-se o herói da Antiguidade num «cavaleiro exemplar», num «novo herói» castrense e religioso (PINTO, 2012, p. 21). É o contrário do que se afirmará no Renascimento, quando existe uma procura mais genuína dos exemplos clássicos, sem qualquer deturpação.

$\mathrm{Na}$ construção mítica da monarquia portuguesa são visíveis duas vias de entendimento, sendo a primeira aquela que diz respeito aos modelos de personagens predestinados para o exercício do poder, em que as virtudes os colocam acima de todos os outros; a segunda é a que mimetiza arquétipos míticos e lendários, nacionais ou estrangeiros. D. Afonso Henriques e D. Afonso IV são os que melhor se adaptam aos dois modelos, enquanto os restantes monarcas se representam apenas pela segunda via (FERNANDES, 2005, p. 121). Quando nos referimos às representações de herói clássico, falamos em sentido abstrato, e não só físico e imagético. Com certeza que haveria certas figuras clássicas, representadas pela arte e pela literatura, com que o rei medieval se gostasse de comparar, e até copiar, refletindo assim um modelo propagandístico cada vez mais definido.

O mundo romano mostrou uma grande preponderância no que diz respeito aos modelos criados para o príncipe perfeito. Entre os principais protótipos contamos César Augusto, que influencia o rei medieval com sua imagem de poder imperial, estabelece o mito do imperador e utiliza sua imagem como propaganda da sua autoridade e poder. Para além disso, seu tempo é considerado, por alguns autores na Idade Média, a preparação do terreno para a vinda de Jesus Cristo. O imperador fica, assim, ligado às raízes do Cristianismo, transformando-se no modelo a seguir pelos reis medievos. Também nos specula principis, literatura de carácter político, moral, pedagógico e normativo que desenha o rei ideal, sua influência é notória, em grande parte devido ao seu Res Gestae no qual se definem os princípios primordiais do seu governo - auctoritas e potestas - assim como as suas virtudes - uirtus, clementia, iustitia e pietas. O crédito desta figura aos reis cristãos medievais não teve a ver apenas com sua dúbia dimensão que oscila entre o poder temporal e o poder divino, mas também no que diz respeito à questão da sua imagem como herói militar, perspectiva que acompanha, também, o imaginário de figuras como Alexandre Magno e Júlio César.

Constantino, em decorrência da sua conversão ao cristianismo, vem marcar o início da contemplação do imperador não como deus, mas como mediador entre o mundo terreno e o divino, e em que o governo deve ir ao encontro da imagem do seu Deus. Este processo de conciliação entre o rei e Deus teve grande difusão no mundo medieval, havendo muitos monarcas que se intitularam «vigários de Deus» ou «ministros de Deus»(FERNANDES, 2005, p. 54). Como reflexo de Deus na 
Terra, o monarca seguia o exemplo de Jesus Cristo. O rei é o escolhido de Deus para o representar em terra, e a iconografia de Cristo é adotada como símbolo real. A cerimônia de unção aproxima o monarca terreno a Cristo, tornando-o um ser santificado, o ungido.

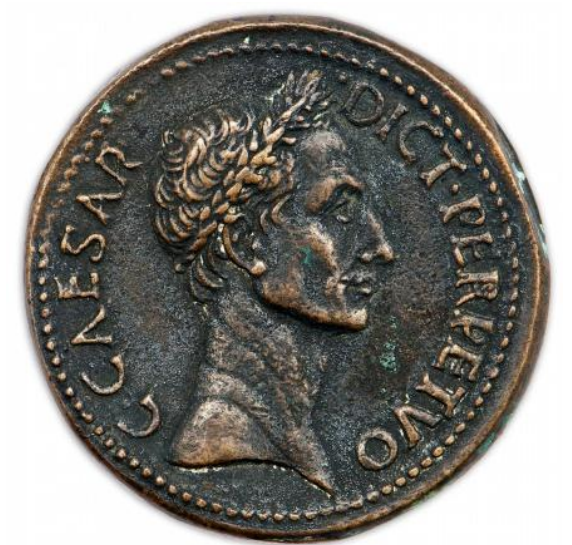

Fig. 2 - Moeda romana com a efígie de Gaio Júlio César

O poder régio medieval constitui-se por duas vertentes herdadas da Antiguidade: do período romano, auctoritas e potestas, e de herança cristã, a dignitas, concedida pela sagração, e a maiestas.

Para além destas, outras figuras se destacaram no imaginário coletivo medieval. Neste sentido, é incontornável a figura de Alexandre Magno. É a personagem perfeita para transmitir uma mensagem de poderio militar, de conquista, de bravura e determinação, mas também de sabedoria e inteligência, geralmente ligada pelos autores medievais a Aristóteles, seu tutor, englobando-se assim todos os requisitos de que se deve compor o rei medieval. Ainda no mundo romano estas características foram utilizadas como modelo, registando-se até um imitatio Alexandri, visto como um protótipo da uirtus (FERNANDES, 2005, p.13). Em Portugal, se dúvidas houvesse sobre o conhecimento da história e influência de Alexandre, rapidamente elas ficariam dissipadas pela descrição da biblioteca, por exemplo, do infante D. Pedro, em 1466, onde vemos um poema de Alexandre en ffrances (BRAGA, 2005, p.359). Há de se ter em conta, ainda, que a história de Alexandre, neste período, foi transformada num romance de cavalaria (ENGELS, 1998, p. 15-24), o que a tornou mais atrativa. Para além disso, tal como o rei medieval a figura deste herói foi progressivamente transformada num representante de Deus na Terra, numa figura mais lendária que histórica, sendo considerado o precursor de Constantino, como o grande fundador do Império do Oriente. Em termos artísticos, não possuímos em Portugal nenhum exemplo que tenha sobrevivido até nossos dias nem temos notícia de alguma representação desta figura. No entanto, 
em França, por exemplo, é uma temática recorrente nas iluminuras, onde é representado como um cavaleiro com armamento tipicamente medieval e com insígnias reais, aproximando-se da imagem geralmente associada ao rei deste período, conferindo-lhe, assim, um carácter intemporal.

Outros exemplos da antiguidade que influenciaram o rei medieval foram os reis de Israel e de Judá, descritos no Antigo Testamento, David, Saul, Salomão e Josias, sobretudo no que diz respeito à devoção a Cristo e ao divino e no exemplo do «bom rei» (eleito por Deus e fiel e servidor deste, deve respeitar as leis e proteger os súditos, reinar em paz e justiça), mas também reis guerreiros e sabedores. Salomão na literatura medieval é aproximado a Alexandre. São vistos como dois exemplos da realeza divina, já que são «fundadores e guerreiros, sacerdotes e reis, profetas e taumaturgos» (FERNANDES, 2005, p. 17-41), e a sua presença nos chamados «espelhos de príncipes» é assinalável. Da mesma forma, as representações artísticas dos reis bíblicos na Idade Média, muitas vezes junto a imagens dos reis cristãos contemporâneos à obra, mostravam à Cristandade o arquétipo do rei perfeito. Garantiam, esses reis bíblicos, a legitimidade dos monarcas medievais e da sua descendência e lhes eram equiparados. Reis da Antiguidade e reis medievais são representados em conjunto no imaginário artístico medieval, verdadeiro processo legitimador.

Não podemos esquecer a existência dos chamados «Os Nove Virtuosos», referenciados por João Longuyon nos inícios do século XIV, que aglomeram os principais homens honrados a ter em conta como protótipo o homem medieval e, sobretudo, o ideal de cavaleiro, matéria a que os monarcas com certeza que não seriam avessos. Encontramos entre estes homens três pagãos (Lei Pagã), Heitor, Alexandre Magno, Júlio César, três judeus (Lei Antiga), Josué, Judas Macabeu, David, e três cristãos (Nova Lei ou Lei Cristã), Artur, Carlos Magno, Godofredo de Bulhão (KEEN, 2008, p. 145-198). Também os modelos para o cavaleiro ideal, o qual com certeza também influenciou a conduta do rei medievo, provêm de três linhas de literatura principais, a Matéria de Roma, histórias relativas à Antiguidade Clássica, a Matéria de França com preponderância para as histórias de Carlos Magno, e a Matéria de Bretanha, com as histórias em volta do Rei Artur e seus cavaleiros (FERNANDES, 2005, p. 215).

Quando nos referimos aos escritos que pretendem desenhar as virtudes e deveres do príncipe perfeito - os «espelhos do príncipe» surgidos na Alta Idade Média -, a influência do pensamento de Platão e Aristóteles ${ }^{4}$ é marcante, tal como as obras de Isócrates, Xenofonte e Díon Crisóstomo (BUESCU, 1996, p. 263), utilizando-se os heróis da Antiguidade como exempla, quer a origem dos textos seja canônica ou leiga. Em Portugal, sabemos da existência do primeiro tratado escrito apenas entre 1341 e 1344, de autoria do português Álvaro Pais e intitulado Speculum Regum. 
Baseado num molde aristotélico, descreve os direitos do monarca, mas também as virtudes necessárias ao bom governante, destacando a prudência, justiça, fortaleza e temperança. Depois, já em 1496, surgia o De Republica Gubernanda per Regem, de Lopes Rebelo.

Para além destes teremos de sublinhar outras obras que, embora não sejam abertamente «espelhos», têm o mesmo pendor moralista e pedagógico destes, entre os quais se encontram o Leal Conselheiro, o Livro da Ensinança de Bem Cavalgar toda Sela de D. Duarte, o Livro da Virtuosa Benfeitoria do Infante D. Pedro. Em todas estas obras, embora sob grande influência cristã, há grande preponderância da obra de Egídio Romano De Regimine Principum, mas não deixa de existir uma grande base de obras de Aristóteles, Cícero e Sêneca (BUESCU, 1996, p. 46-48).

Consideremos a profícua importação e tradução de muitas obras estrangeiras, contemporâneas e anteriores a seu tempo. Em geral, a função governativa do monarca devia respeitar três premissas principais: cumprir os desígnios da Igreja e obedecer a Deus, ao poderio militar e ao rei-guerreiro, a que também podemos associar a sabedoria e inteligência do monarca e garantir a prosperidade dos seus domínios e súditos a todos os níveis. Estes documentos corporizam e englobam as virtudes de todos às figuras históricas e também lendárias que referimos até aqui, formando-se um ideal de rei.

Afonso I de Portugal representa esse ideal. Mas o que o liga às representações do mundo clássico? O que o define enquanto continuidade de um modelo mediterrânico de construção e definição de poder? Como encontrar num rei da Cruzada elementos que o consagrem naqueles modelos? Tomemos como paradigma relacional um episódio consagrado no seu reinado e tema recorrente da historiografia portuguesa: a sua aclamação como rei de Portugal. A tradição de tal aclamação radica no que vem descrito, pela primeira vez, na Crónica Galego-Portuguesa de Espanha e Portugal e incluída na IV Crónica Breve de Santa Cruz. Texto lacônico e conciso, nunca refere a aclamação, ${ }^{5}$ embora ponha em realce a «realeza» do princeps português no contexto das suas capacidades enquanto militar. Toma por armas as cinco quinas. D. Afonso Henriques muda em Ourique. Assume ali outra dimensão, adquire um novo pendão, integra uma outra essência. As quinas, mais do que reis mouros vencidos, afirmam Portugal independente e garantido por uma nova magistratura - o rex. Mas, voltemos ao contexto da aclamação na perspectiva de aí encontrarmos a expressão de uma velha representação do mundo romano: o título de imperator atribuído pelos legionários ao seu legado no campo de batalha. Era por aclamação das forças militares que assim expressavam o reconhecimento pelas qualidades demonstradas pelo seu chefe 
militar. Contudo era sempre depois da batalha. O contexto romano que definia se o legado e suas legiões poderiam marchar em triunfo perante a população de Roma após uma campanha atribuía uma importância decisiva àquele acontecimento marcial.

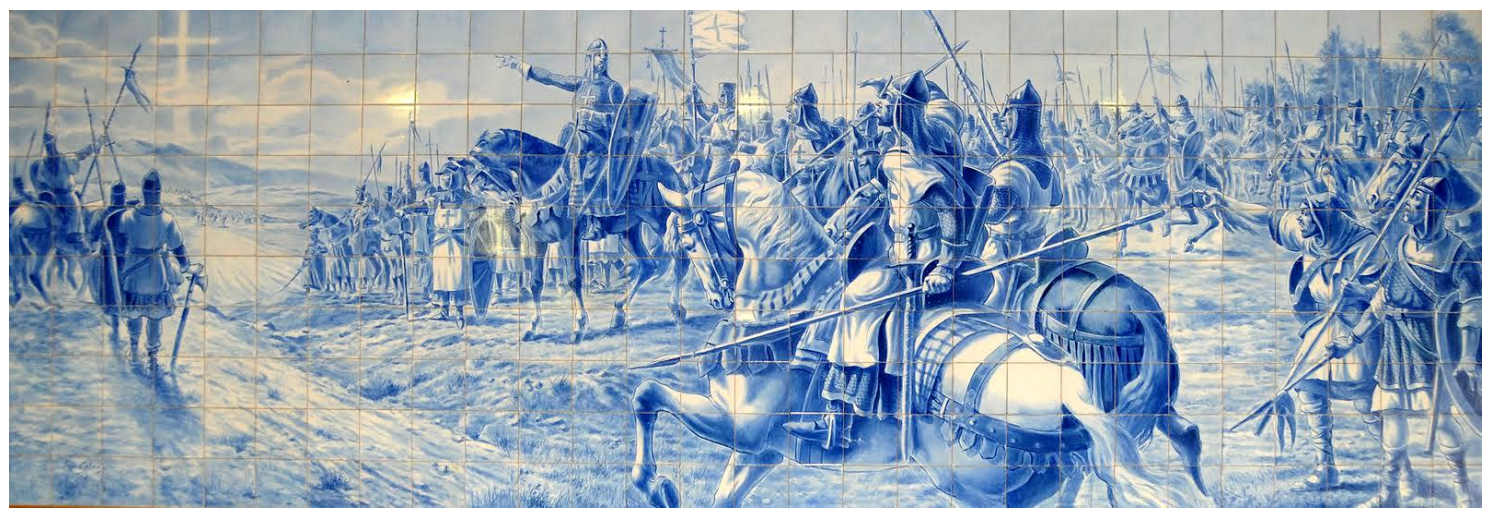

Fig. 3 - Afonso Henriques na batalha de Ourique, azulejo de Jorge Colaço.

Foi semelhante o que os guerreiros portugueses fizeram em Ourique ao seu comandante. Pelo quadro da tradição, parece que não. Seguindo a narrativa do conde D. Pedro, o autor que em 1344 escreve a Crónica Geral de Espanha (CRÓNICA, 1953-1983), ali encontramos, pela primeira vez, uma expressão curiosa: «...Mas, antes que entrasse ẽna batalha, conta a estória que os seus que o alçarom por rey. E des entõ se chamou rey de Portugal» (CRÓNICA, 1953-1983, p. 224 ss). Será a mesma tradição que encontramos nas legiões de Roma? Tomemos a expressão «alçarom», o que significa? Que o levantaram? E como o fizeram? Mais uma vez, e de acordo com a velha tradição cronística portuguesa, percebemos que o colocaram em cima do seu escudo (ou pavez) e assim, alçado, o aclamaram. Parece muito verosímil esta imagem, mas ela radica mais na tradição germânica de aclamar os seus chefes, de pé, sobre o seu escudo, por altura das batalhas. Encontramos, nesta tão importante representação da capacidade viril, masculina, outra tradição, um pouco diferente da romana, mas coeva desses tempos.

Reparemos ainda que na descrição dos acontecimentos de Ourique D. Afonso Henriques é alçado e aclamado sobre o seu escudo antes da batalha ser travada. Não é aclamado depois de vencer o confronto. A tipologia funcional germânica está aqui bem presente com toda a sua carga simbólica. Sabemos, por comparação com outros costumes de outros reinos europeus, que esta cerimônia iniciática de aclamação de um novo soberano era muito comum. Em reinos como o de 
Navarra seguia-se este costume. Será este mesmo ritual o que a Crônica de 1344 descreve? Se observarmos o que José Mattoso (MATTOSO, 2006, p. 120-121) comenta a este respeito na biografia que fez do primeiro rei de Portugal, é interessante perceber a importância que o escudo - o objeto propriamente dito - assume em todo o contexto fundacional. Faz-se um rei. Reza a lenda que este escudo teria sido colocado sobre o túmulo do rei, no mosteiro de Santa Cruz de Coimbra, e que caía da parede, sem que ninguém lhe tocasse, sempre que morria um rei de Portugal. Nunca saberemos qual foi o escudo usado pelo rei na batalha de Ourique, contudo é muito relevante que a sua forma e as insígnias nele representadas se assumissem como elementos constitutivos e representativos dos selos reais usados nos documentos das duas primeiras chancelarias régias portuguesas.

O escudo do rei, sua principal arma defensiva (como a de qualquer cavaleiro medieval), assumia um carácter mágico. Transformava-se num recurso simbólico representativo de um dos elementos mais estruturantes na definição da forma como se detém o poder soberano. Ao ser alçado sobre o

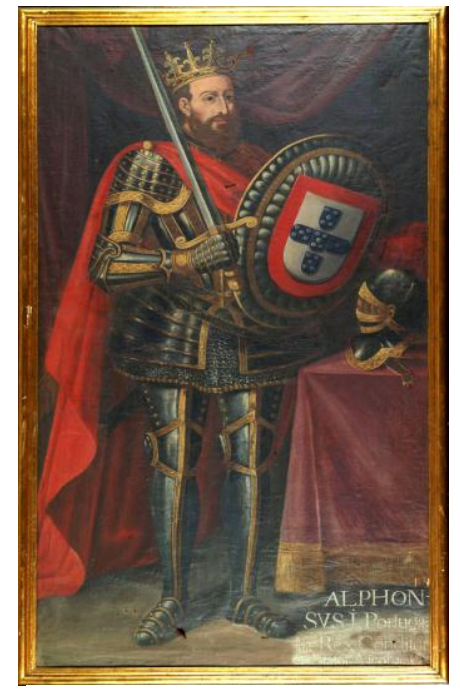

Fig. 4 - D. Afonso Henriques escudo, levantado pelos seus homens de armas, consagrado antes de um confronto armado contra os inimigos da fé, Afonso é feito rei dos portugueses, cumprindo uma tradição europeia em que a dimensão militar assume papel fundamental. Torna-se o escudo uma relíquia sagrada. Um objeto profano que assume na dimensão portuguesa, no contexto de um reino que agora emerge (e emerge pela força das armas), uma expressão mimética, semelhante à dos escudos dos reis germanos, está para nós no mesmo nível dos famosos tesouros da Britania de Artur e do druida Merlin. A espada e o escudo de D. Afonso Henriques são itens mágicos, semelhantes à famosa Excalibur, ao cálice sagrado ou à lança que matou Cristo na cruz.

Buscamos as representações clássicas, é verdade. Sentimos nos reis medievais portugueses a mesma identificação com as grandes personagens do Mundo Clássico. Mas há mais do que isso. Existem outras representações das várias dimensões do poder. $\mathrm{Na}$ lenda de Ourique bebem-se outras tradições. Cristianizadas, claro. Mas potentes, fazedoras de reis. Alexandre Magno, Júlio César e Artur, rei dos Bretões, juntam-se neste ocidente ibérico onde um novo rei é feito por «velhas» formas vindas dos confins da Germânia. E, noutro sentido, esta cerimônia, a de alçar (fazer) um rei é apenas de contexto militar - é propiciatória, mágica, simbólica - mas é feita, apenas, em contexto masculino. Ao elemento feminino está vedada esta parte da construção de uma nova potência. Mais 
do que uma legitimação, este processo de aclamação está prenhe de conteúdo militar. Só ali, na dimensão da guerra, se pode realizar. Só ali, entre os homens que vão morrer de armas na mão, adquire sentido.

O significado militar do rex português implica, também, a aquisição e consolidação das periferias, a redimensionação e a estruturação do reino sobre grupos heterogêneos, especialmente vocacionados para a guerra de fronteira e predispostos ao desenvolvimento de processos feudais, mitigados pela existência de poderes centrais em ambos os blocos: monarquias cristãs e califas almóadas (VARANDAS, 2010, 151-196). No século XIII todo o Gharb é uma sociedade de fronteira, repleta de habitats militarizados e em constante estado de guerra contra o outro bloco, exatamente situado sobre o outro lado da fronteira e, também ele, profundamente militarizado. Para ambos, a volatilidade do espaço, a invisibilidade da linha divisória e a «livre-circulação» são elementos comuns, padrões normais de comportamento, cuja opção predominante é a resistência ao centralismo. As regras da Reconquista trazem contornos diferentes a estas sociedades de fronteira. A guerra feita às cidades do Gharb al-Andalus pelos reis peninsulares ao longo do século XIII imprime mudanças radicais ao nível dos comportamentos dos núcleos e caudilhos fronteiriços, de ambos os lados, ao estruturar-se sobre estes novos modelos administrativos e de assimilação cultural. Mesmo unidades militares autônomas e pouco valorativas das identidades nacionais, como as Ordens Militares, imprimem sobre os territórios que lhes são doados pelos reis as regras do sistema central. E a construção dos centros, em que as monarquias se afirmam como modelo definidor, vê a fronteira de forma diferente, como algo estável, definitivo, impermeável. Depois de Sancho II, depois de Afonso III, depois de Fernando III ou Afonso X não mais se verá o livre andar dos homens fronteiriços pelas terras da marca, porque já não há marca. A fronteira é afinal a última expressão centralizadora de uma imagem construída - a do rei. Define os limites dessa emanação «masculina» que é o reino. Rei e reino formam a mesma matéria, construída pela força das armas e garantida na suprema representação dos poderes régios. A imagem do rei medieval português, plena de futuras potencialidades, contém em si o modelo e a substância afirmados na longa evolução das monarquias da Antiguidade.

Afonso Henriques, o primeiro dos reis portugueses, representa David, Alexandre Magno, Júlio César, Augusto, Constantino, o visigodo Recaredo, Artur e Carlos Magno. Representa, no limite, Cristo e, assim, a legitimação e a «justeza» da guerra contra o Islão a partir da prática guerreira. As campanhas da Reconquista, que representam um continuado ato de guerra e a fixação de novas formas de obediência política, continuam o debate iniciado no seio da Cristandade sobre a 
legitimação ética, moral e política da atuação militar. A confrontação em larga escala contra o islamismo precisa do rei como elemento catalisador de uma nova doutrina de Cruzada. Ricardo, Coração de Leão, no Outremer, ou Afonso Henriques, o Conquistador, na Hispânia, assumem, definitivamente, essa essência definidora de uma Christianitas suportada pelo elo da prática do poder com o exercício da guerra. $\mathrm{O}$ rei - até aqui representante de uma ideia de res publica, em que a guerra praticada se definia como «justa», definida como um instrumento de castigo sobre o adversário «culpado» e que visava à celebração de uma «paz equitativa» - vê na nova concepção de uma doutrina de cruzada, definida pelo conceito operativo «guerra santa», a desvalorização do seu poder temporal. A cruzada define uma nova superestrutura, uma Respublica Christiana em que a autoridade da Ecclesia prepondera. É o que acontece na Península Ibérica, na qual a Reconquista, processo militar de longa duração e envergadura, se organiza não como «guerra justa», porém mais como «guerra santa», em que o fator internacional e a ligação à Santa Sé se tornam evidentes. Contudo, as campanhas militares continuam a depender, sempre, do rei. Embora em escala internacional cada teatro de operações dependa de monarcas específicos, definidores de políticas concretas e de ações determinadas, já que em alguns casos, como o de Portugal, não está apenas em causa a contribuição para um plano maior - o da Cruzada -, joga-se também a possibilidade da independência.

Acompanhando a consolidação da autonomia do reino de Portugal na Península Ibérica e as necessidades impostas pelo alargamento de um território descontínuo (no norte de África, na costa ocidental africana e nas ilhas atlânticas), multiplica-se no Portugal medieval o recrutamento sistemático de homens para a guerra. Situando-nos somente nos finais de 300, podemos verificar, na cronística sustentada pela documentação da chancelaria régia, todo o planeamento e realizações bélicas de D. Nuno Álvares Pereira a serviço da causa de D. João I; anos mais tarde, D. Duarte promulgará os regimentos dos coudéis, besteiros do conto e galiotes, e redigirá o regimento para a campanha de Tânger; ${ }^{6}$ já em tempos do regente D. Pedro, as Ordenações Afonsinas, ${ }^{7}$ concluídas em 1446 e publicitadas em 1447, incluirão no Livro I um «Regimento da Guerra», assim como o regimento de vários ofícios relacionados: condestável, marechal, almirante, capitão-mor, alferesmor.

O rei medieval é sempre um guerreiro. Efetivamente, sua função de proteger os bons, castigar os maus, assegurar a integridade territorial do reino, defender a cristandade perante o infiel (VENTURA, 2010b, P. 125-141) poderá, esgotadas as tentativas a que chamamos diplomáticas 
previstas no jus ad bellum, exigir-lhe a declaração de guerra, à qual se seguirá toda a preparação e o comando da luta armada. O rei é o senhor da hoste, como vem expresso no regimento do condestável acima referido. Quanto a sua participação pessoal nas campanhas, esse é um debate cada vez mais comum à medida que nos encaminhamos para a modernidade.

Nos finais da Idade Média em Portugal, D. Afonso V assume-se como um rei combatente, participando nas campanhas do norte de África e na incursão pelo reino de Castela, até seu desfecho em Toro (1476). O rei português acompanha a sua efetiva atividade bélica com a escrita de um tratado hoje perdido, intitulado Tratado da milícia, conforme o costume de batalhar dos antigos portugueses (VITERBO, 1904). A compatibilização entre o cultivo das letras e o exercício das armas, que Camões imortalizará, é, em si mesma, evocativa do modelo ciceroniano no tratado $D e$ officiis, tão familiar à corte avisina. Desconhecemos que «costumes de batalhar» teriam sido descritos naquele Tratado e até que ponto seguiam conhecimentos factuais ou quaisquer modelos prévios.

Sabemos que D. Afonso V fora educado sob a influência do infante D. Pedro e com aproximações ao humanismo italiano pela mão de Mateus Pisano, que chega à corte portuguesa em 1435. Todavia, mais do que a obra isolada deste rei importa o conhecimento dos tratados militares da Antiguidade que chegaram à corte de Avis, bem inserida nos círculos (também) culturais peninsulares e outros, nomeadamente da Inglaterra e da Borgonha. Convém referir, como exemplo, que na biblioteca de D. Duarte existia uma Guerra da Macedónia, uma História de Tróia e um livro de Aníbal, assim como a Vida e Feitos de Júlio César e a obra de Valério Máximo.

O mais célebre de todos os tratados é o já citado Epitoma, de Flavius Vegitius Renatus, sobejamente conhecido em Portugal e, com toda a probabilidade, mandado traduzir pelo infante D. Pedro (MONTEIRO, 2007; VEGÉCIO, 2006, 133ss). Com ele chega, sem passar pela pena de Afonso X, toda a tradição militar da Antiguidade. Os elementos que as Siete Partidas carreiam estão agora estruturados num texto bem mais completo e próximo dos tratados fundacionais da arte da guerra. Está por estudar a real influência na corte de Avis de D. Alonso de Cartagena, bispo de Burgos. Não nos referimos exclusivamente às suas estadas em Portugal como embaixador de Castela, no decorrer das quais travou amizade com D. Duarte, mas sim ao impacto da sua obra. Destacamos, pois nos interessa para este apontamento, o Doctrinal de los cavalleros, provavelmente redigido em 1444 e impresso em 1487. Ainda que não tenhamos provas de que esta obra era conhecida na corte portuguesa, é improvável que o Doctrinal, circulando na corte castelhana, não tenha sido conhecido em Portugal. Aí, a par com as referências eclesiásticas, 
patrísticas e bíblicas, figuram autoridades que são os seus modelos clássicos: Aristóteles, Cícero, Valério Máximo e muitos outros, com destaque para Vegécio.

A representação visual do rei medieval português é muito rara. Exprime-se, com grande relevância, na tumularia régia por meio dos jacentes. A imagem do rei é sempre

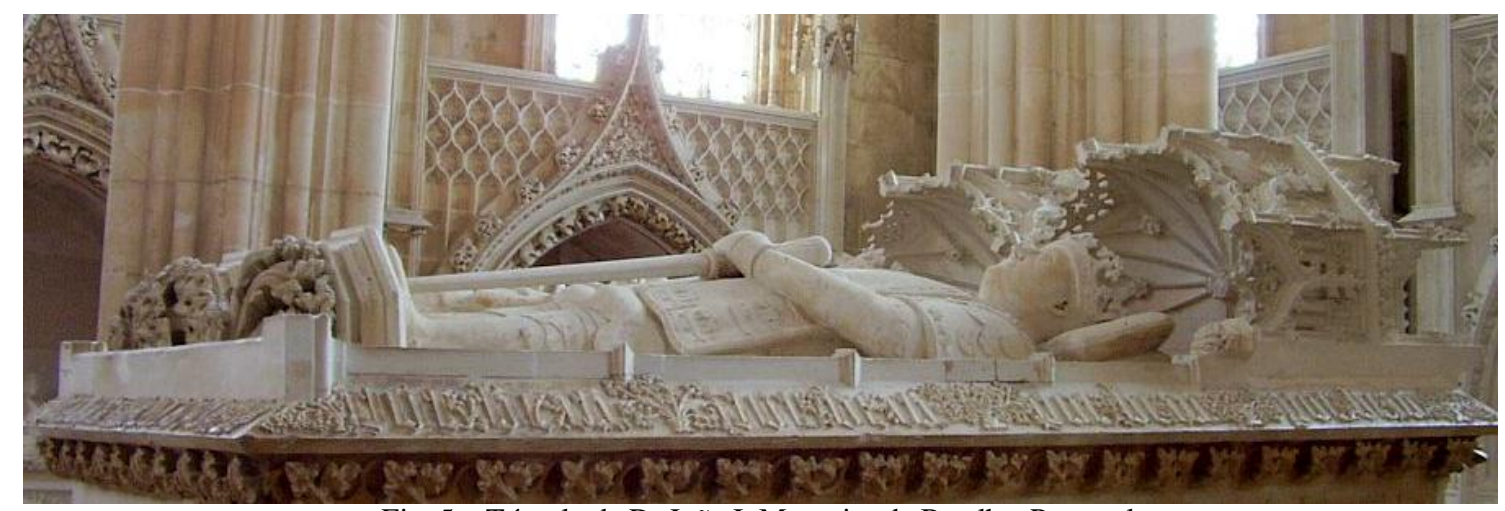

Fig. 5 - Túmulo de D. João I, Mosteiro da Batalha. Portugal.

uma forma de propaganda e uma necessidade de legitimação do seu poder. Assegura, também, a legitimidade da sua descendência. Afirma-se líder por direito. Visto que durante a maioria do período medievo o trono português não foi colocado em causa, este fato pode justificar a ausência de imagens do rei português. Com efeito, tomando como exemplo Castela, Leão, França ou Inglaterra é evidente a profusão de imagens régias sempre que o poder do monarca é colocado em causa (FERNANDES, 2005, p. 383). Obviamente, razões de várias naturezas poderão, também, ter ditado a sua destruição. A representação do rei em todo o seu aparato, com as insígnias do poder real, que em si só formam os atributos da soberania, reafirma a autoridade e prestígio do monarca perante seu território e seus súbditos. Mais que um retrato fidedigno das características físicas, procura-se uma imagem preponderante do rei no seu conjunto. Esta preponderância era conseguida pela inclusão das insígnias, pela armadura envergada de forma imponente, pela posição confiante, definida e poderosa da personagem e, ainda, pelo local onde a representação do rei é colocada.

As Tapeçarias de Pastrana constituem um grupo de quatro tapeçarias que representam a conquista das cidades marroquinas de Arzila e Tânger pela força militar portuguesa, comandada pelo rei D. Afonso V, em 1471. São um dos maiores legados da arte portuguesa dos finais da Idade Média e uma das fontes principais de estudo das ações militares em Marrocos, mas também, e sobretudo, formam um dos mais importantes núcleos de tapeçaria no contexto europeu, em grande 
parte devido à representação de um acontecimento contemporâneo, sem recorrer abertamente a alegorias mitológicas.

A representação da tomada das cidades nas tapeçarias é dividida em dois grupos principais: um primeiro, que diz respeito às três tapeçarias da conquista de Arzila, «Desembarque em Arzila», «Cerco a Arzila» e «Assalto a Arzila»; e um segundo grupo que retrata a «Tomada de Tânger». O núcleo é datado do último quartel do século XV, embora sem conseguirmos precisar uma data, já que não existe qualquer registo escrito sobre elas. Relativamente à sua manufactura, foi avançado, com alguma segurança, pela comparação de técnicas que teriam sido concebidas na Flandres, provavelmente na cidade de Tournai, no atelier do famoso tapeceiro Pasquier Grenier.

Para nosso estudo, essas tapeçarias constituem um documento primordial, já que englobam em si três representações do rei D. Afonso V, mas também do seu filho, príncipe herdeiro, o futuro D. João II. Apesar de não descreverem um acontecimento de cariz clássico, quando as comparamos com outras obras do mesmo período achamos certas tentativas de aproximação a modelos cristalizados de guerra e do herói clássico, sobretudo na figura do rei. De fato, temos um exemplo paradigmático, curiosamente uma obra do mesmo tapeceiro, Pasquier Grenier, e datado do mesmo período, o que nos permite um maior entendimento da analogia da conquista das cidades marroquinas e das guerras travadas em ambiente clássico: as tapeçarias da série Guerra de Troia. Embora representando temáticas distintas, a composição é muito semelhante, tal como a representação dos heróis se assemelha muito à imagem de D Afonso V desenhada nas de Pastrana.

Se considerarmos a hipótese de José de Figueiredo, os cartões que deram origem às tapeçarias foram da autoria de Nuno Gonçalves, pintor régio de D. Afonso V desde 1450 e autor dos famosos Painéis de S. Vicente (Museu Nacional de Arte Antiga, Lisboa), e seguindo a premissa de Francisco de Holanda, justificada depois por Adriano de Gusmão (GUSMÃO, 1951), sobre o «italianismo» deste pintor. A grande maioria dos estudiosos refere apenas o «sabor» flamengo, aliás muito evidente, das suas obras. Porém, teremos de ter em conta pormenores da sua pintura que nos levam aos artistas do Quattrocento, como a representação da figura humana próxima do real, mas ao mesmo tempo numa grandeza ideal, «uma monumentalidade quase escultórica» (MARKL, 1987, p. 31), que nos reporta já para os valores estéticos da Antiguidade Clássica. Essa recuperação de modelos clássicos será mais evidente, chegando a ser até direta, particularmente em Rafael e Miguel Ângelo. Esta predileção conferida às personagens aproxima Nuno Gonçalves dos cânones clássicos e do pensamento renascentista italiano. Ali, o Homem torna-se progressivamente o centro convergente do Mundo e a criatura privilegiada por Deus. Esta premissa é visível nos Painéis e nas 
Tapeçarias de Pastrana. Estas representam o melhor exemplo (chegado até nós) de um retrato de um rei português: D. Afonso $\mathrm{V}$, a que se juntou o infante $\mathrm{D}$. João.

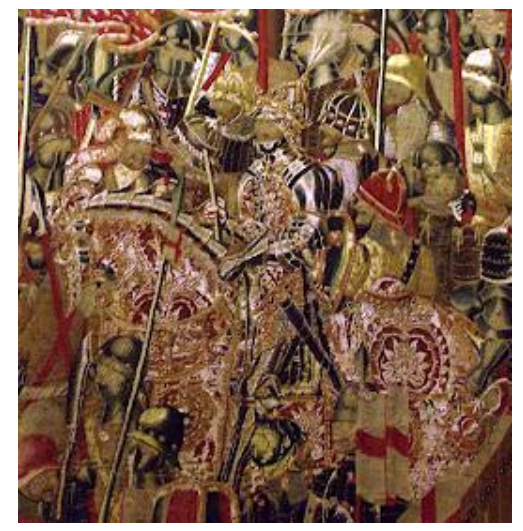

Fig. 6 - D. Afonso V, tapeçarias de Pastrana

Nas tapeçarias que representam o cerco e o ataque a Arzila, as imagens de pai e filho (soberano e seu sucessor) estão perfeitamente alinhadas em cada uma das extremidades da composição. Apresentam-se de perfil, ao estilo dos retratos italianos, sobretudo florentinos, do mesmo período, inspirados nas moedas romanas marcadas pelos retratos dos seus imperadores. São as únicas personagens montadas e, pelo seu armamento profusamente trabalhado (sobretudo no que diz respeito ao do rei), não deixam dúvidas quanto a sua identificação enquanto figuras régias.

Da mesma forma, esta representação estática e retilínea do rei majestosamente montado, corajoso e confiante, armado de arnês completo, elmo coroado (símbolo da soberania suprema) e carregando na sua mão o bastão de comando, denuncia-o como o grande chefe militar daquela investida. Isto é usual na pintura renascentista. É interessante como D. Afonso V preferiu ser representado em majestade e em contexto de batalha, junto do seu exército, dos seus nobres e do seu filho, não guardando para si toda a atenção de um retrato individual entronizado (representação inspirada no Cristo em Majestade) ou sob um arco triunfal, sem outras personagens que pudessem ofuscar o seu poderio.

É possível que estes retratos tenham existido para além das Tapeçarias e que não tenham chegado até nós. Aliás, desde 1435 a arte do retrato se tornou um gênero per se, e com uma importância crescente, focando-se sobretudo nas linhas do rosto. Mas não podemos deixar de sublinhar os rostos de todas as personagens das tapeçarias, cada um com traços de fisionomia próprios, embora muitos se mantenham ocultos pelos capacetes e babeiras. De qualquer das formas 
podemos especular sobre a singularidade desta representação. É discutível qual delas cumpriria o fim a que se destinava, já que as duas representações do monarca transmitem uma mensagem muito semelhante. Podemos dizer que, nas Tapeçarias, D. Afonso V surge como líder do seu povo e o grande comandante do seu exército, aproximando-se do sentimento clássico que representa o imperador que recebe, por transferência divina, o poder. Ou, seguindo as Escrituras, à imagem do rei David como o «pastor» do seu povo. Esta ligação àquele rei hebreu é recorrente neste período, verificando-se até muitos monarcas que se afirmam «novos David» (FERNANDES, 2005, p. 31). Pelo seu carácter militar, mas sobretudo como fundador de uma geração de reis que daria origem a Jesus Cristo, David é associado à derrota dos filisteus (o mal), e em contextos medievais é feita, sempre, uma analogia entre esta vitória e o triunfo do rei cristão sobre o inimigo muçulmano.

D. Afonso $\mathrm{V}$ é representado em mesmo tamanho que os seus súditos, mostrando não ter qualquer poder sobre-humano. Fora a sua espada e a sua determinação, ele é um homem comum, mas com enorme desejo de guerra contra o infiel, podendo até equiparar-se a D. Afonso Henriques, o primus inter pares que fora aclamado no campo de batalha. D. Afonso V e D. João são os cavaleiros líderes do exército, representam os modelos do cavaleiro ideal e mostram como o seu governo é assente no pensamento militar. A espada que o monarca levanta e que instiga ao ataque é um emblema do poder soberano, da conquista, inerente a todos os reis portugueses e a todos os monarcas ocidentais integrados na Respublica Christiana. E a representação da soberania régia acentua-se com a presença, naquelas imagens, do bastão de comando, suprema insígnia de autoridade e de liderança do rei português.

Podemos, sem dúvida, aproximar esta forma de representação à arte clássica, sobretudo romana, e depois aos retratos que esta influencia na Itália renascentista. Quando falamos de arte romana, a figura que mais terá influenciado D. Afonso $\mathrm{V}$ na encomenda deste seu retrato foi César Augusto, considerado o grande fundador da arte imperial, transmitindo-se uma imagem divinizada, mas associada ao poder militar. O primeiro imperador romano utilizou a arte pública como elemento importante na sua propaganda política e como processo de construção de um sistema imperial radicado na imagem como representação do poder. Não excluindo essa dimensão a D. Afonso V, a sua imagem assume um carácter mais restrito. É um instrumento político de corte, de interior, com um objetivo ou público-alvo mais definido do que o de Augusto. Retrata-se uma glória específica, um poder definido, um rei e um reino.

Sublinhamos que esta influência da propaganda imperial romana teria de ser considerada, para lá do sentido bélico, uma representação da Pax romana, resultante, afinal, dos triunfos 
militares. São exemplos a recuperação das estátuas equestres, inspiradas na de Marco Aurélio, a única que sobrevive nos nossos dias, a estátua de Donatello, representando o condottieri Erasmo da Narni, conhecido como Gattamelata, datada de cerca de 1450, e a que introduz no Renascimento aquela tipologia escultórica. Também na pintura, o número de cavaleiros representados era crescente. É o que se passa com pintores como Paolo Uccello e que em muito se aproximam desta representação como que imperial de D. Afonso V.

Podemos, ainda, estabelecer um paralelismo com o mosaico que representa Alexandre Magno montado e combatendo na Batalha de Issus. Ali, o grande rei macedônio tem o corpo virado de frente para o espectador, olha fixamente o caminho, mas mostra a face de perfil. De fato, até no armamento D. Afonso V se aproxima da pintura de Uccello. O rei português veste-se com um arnês de aparato, pouco decorado, e sem inspirações no equipamento militar clássico, ou com decorações que o fizessem denunciar, ao contrário do que vemos nas armaduras de Carlos V, em Espanha.

De fato, embora a postura com o bastão de comando se aproxime dos trabalhos de Donatello, que levou muito mais à letra a recuperação da imagem clássica do imperador romano, e em que, pelos cânones, o cavalo estaria em movimento, nas Tapeçarias de Pastrana o animal mostra-se estático. Qualquer possibilidade de movimento escapa a nosso olhar, pois a armadura do cavalo e o tecido que o cobre ocultam as suas patas. Esta estaticidade do animal, a que se junta a do cavaleiro, pode estar relacionada com o ideal de representação da majestas, em que o corpo é o ponto fulcral da composição e por isso deve estar imóvel, como vemos nas imagens dos faraós egípcios ou nos imperadores romanos, ao mesmo tempo que contrasta com a movimentação dos que o rodeiam. Não existe mais nada que faça denunciar esta tapeçaria ou D. Afonso V como tendo alguma inspiração clássica. Essa também pode ser uma das premissas que fez ligar as tapeçarias a Nuno Gonçalves: a inexistência de qualquer fundo arquitetônico com linhas clássicas. Quando nos referimos a Uccello, não queremos dizer que o autor dos cartões tapeçarias foi influenciado por este artista em específico, mas sem dúvida que se inspirou nas representações italianas com evidente relação com o mundo clássico. De fato, a importação de obras italianas para Portugal é visível desde a primeira dinastia e continuou a acontecer até ao século $\mathrm{XV}$, registando-se a presença de mercadores e banqueiros italianos em território português, e destes negócios ainda temos notícia em documentação em número apreciável (DIAS, 1982, p. 29-43).

O espírito de cruzada que vemos representado nas Tapeçarias, e que é muito marcado em D. Afonso $\mathrm{V}$, mas também nos monarcas que o precederam, e esta união do povo sob a alçada de um 
homem que os lidera e do Deus que este representa ostenta uma clara influência de reis cristãos, considerados a base da difusão do cristianismo na Europa, no contexto de uma Ecclesia que congrega a fé com a ação armada e em que o rei é personagem importante. É o expoente maior. O rei da Cruzada, condutor do seu povo no processo coletivo da Christianitas e, por isso, subordinado ao Papa, mantém contudo uma imagem que o liga a outros reis de outras fases de cristianização: Carlos Magno, Artur e Clóvis I. Do grande rei carolíngio resta ainda uma dinâmica propagandística, visível na literatura e na iconografia, e que se recupera nos tempos de D. Afonso V. Mantém-se o paradigma da luta contra infiel, comparando as campanhas nas marcas militares pirenaicas com as operações de grande envergadura que o rei português leva às costas norte-africanas e que se expressam nas Tapeçarias.

As Tapeçarias de Pastrana, pela temática que representam, pelo programa iconográfico que contêm, pela sua dimensão heráldica, matérias que dizem respeito sobretudo ao rei e a seu reino, pela forma como representam os seus homens, pela conquista, pela sua grande dimensão e até pelo texto que apresentam, enunciam uma celebração de poder e de legitimação da supremacia régia. Perpetuam a memória de um rei na sua imagem. Esta obra de arte insere-se num dos três campos de estratégia de afirmação do monarca: ordem do discurso, ordem dos sinais e ordem do cerimonial (BUESCU, 1996, p. 29).

Em conclusão, o rei português, como todos os monarcas europeus do mesmo período, sintetiza as virtudes dos grandes reis e heróis da antiguidade, seus fiéis ascendentes. Mas é, também, o escolhido de Deus. É-lhe fiel e representa-o da melhor forma possível na Terra. A imagem que D. Afonso $\mathrm{V}$ tenta transmitir nas Tapeçarias de Pastrana engloba tudo isso: é o reicristão, o chefe da cruzada que tenta a conquista de terras aos infiéis e que o consegue; é o reiguerreiro e o herói, que luta comandando seu povo em prol da religião cristã, do território e da paz; é o rei-virtuoso e sabedor, que não ignora os seus antepassados e que impulsiona a cultura e o conhecimento. D. Afonso V é um herdeiro legítimo da Antiguidade e do rei-mito D. Afonso Henriques. É, na imagem, o espelho perfeito do monarca do seu tempo.

É o rei que foi e um dia será. 


\section{Referências bibliográficas}

BASCHET, Jérôme. L’iconographie medieval. [s.1.]: Éditions Gallimard, 2008.

BRAGA, Teófilo. História da Literatura Portuguesa, vol. I - Idade Média. [s.1.]: Imprensa Nacional - Casa da Moeda, 2005.

CARTAGENA, Alonso. Doctrinal de los cavalleros. Edição de José Maria VIÑA LISTE. Santiago de Compostela: Universidade de Santiago de Compostela, 1995.

CRÓNICA de 1344 - Crónica Geral de Espanha. Ed. L. F. Lindley CINTRA, 4 vols. Lisboa: Academia Portuguesa da História, 1953-1983.

DELUMEAU, Jean. A Civilização do Renascimento. Lisboa: Edições 70, 1984.

DUARTE, D. Livro dos Conselhos de El-Rei D. Duarte (Livro da Cartuxa). Ed. de João Alves Dias. Lisboa: Editorial Estampa, 1982

DUARTE, Luís Miguel. D. Duarte. Lisboa: Círculo de Leitores, 2005.

ELLENIUS, Allan (ed.). Iconography, Propaganda, and Legitimation. Oxford: Oxford University Press, European Science Foundation, Clarendon Press, 1988.

FERNANDES, Carla Varela. Poder e representação: iconologia da família real portuguesa: primeira dinastia, séculos XII a XIV [texto policopiado]. Dissertação de Doutoramento apresentada à Universidade de Lisboa, 2005.

GOMES, Saul António. D. Afonso V, o Africano. Lisboa: Círculo de Leitores, 2006.

GERRITSEN, Willem P. e Anthony G. van Melle. A Dictionary of Medieval Heroes. Characters in Medieval Narrative Traditions and Their Afterlife in Literature, Theatre and the Visual Arts. Woodbridge: Boydell Press, 1998.

JOÃO I, D. Livro de Montaria feito por El-Rei D. João I de Portugal. Introdução, leitura e notas de Manuela Mendonça. Ericeira: Mar de Letras, 2000.

KEEN, Maurice. La Caballería. La vida caballeresca en la Edad Media. Barcelona: Editorial Planeta, 2008.

MATtOSO, José. D. Afonso Henriques. Lisboa: Círculo de Leitores, 2006, pp. 120-121.

MONTEIRO, João Gouveia. A Guerra em Portugal nos Finais da Idade Média. Lisboa: Editorial Notícias, 1998. 
Quatres Études d'Histoire Militaire Médiévale Portugaise. Coimbra: CHSC / Palimage, 2007.

MUSEU NACIONAL DE ARTE ANTIGA. A Invenção da Glória. D. Afonso V e as Tapeçarias de Pastrana. Lisboa e Madrid: Museu Nacional de Arte Antiga e Fundación Carlos Amberes, 2010.

PERNOUD, Régine e Marie-Véronique Clin. Joana d'Arc. Mem Martins: Europa América, 1993.

PINTO, Ana Paula e outros (org.). Mitos e Heróis. A Expressão do Imaginário. Braga: Publicações da Faculdade de Filosofia da Universidade Católica Portuguesa, 2012.

SACK VILLE-WEST, V. Santa Joana d'Arc. Lisboa: Livros do Brasil, 1994.

SOLER DEL CAMPO, Álvaro (ed.). The Art of Power. Royal Armour and Portraits from Imperial Spain $=$ El art del poder. Armaduras y retratos de la España Imperial. [s.1.]: SEACEX, Patrimonio Nacional, Tf editores, [s.a.].

VARANDAS, José. D. Sancho II, o Capelo. 1223-1248. In: História dos Reis de Portugal, 2 vols. Lisboa: QuidNovi / Academia Portuguesa da História, 2010, pp. 151-196.

VEGÉCIO. Compêndio da Arte Militar. Trad. de João Gouveia Monteiro e José Eduardo Braga. Estudo Introdutório, Comentários e Notas de João Gouveia Monteiro. Prefácio de Maria Helena da Rocha Pereira. Coimbra: Imprensa da Universidade de Coimbra, 2009.

VENTURA, Margarida Garcez. D. Duarte, o Eloquente. In: História dos Reis de Portugal, 2 vols. Lisboa: QuidNovi / Academia Portuguesa da História, 2010, pp. 491-538.

O ofício de rei no Portugal quatrocentista. Teoria e práticas de poder. In NOGUEIRA, C. $O$ Portugal Medieval. Monarquia e Sociedade. São Paulo: Alameda, 2010, pp. 125-141.

VITERBO, Sousa. A cultura intelectual de D. Affonso V. Lisboa: Off. Typ. Calç. do Cabra, 1904.

\section{Notas}

\footnotetext{
${ }^{1}$ Porém, em acontecimentos chave da história de Portugal de finais dos séculos XIV e XV encontramos mulheres excepcionais que, de modo não institucional mas não menos lúcido e eficaz, incitam, esclarecem, apoiam ações bélicas de grande risco. Foi o caso de Iria Gonçalves, mãe do Condestável D. Nuno, de D. Filipa de Lencastre, no debate sobre a conquista de Ceuta, ou D. Leonor, que pressionou a expedição a Tânger.

2 As mulheres não são nunca mencionadas na montaria, a qual é, também, treino militar (v eja-se a obra de D. João I, Livro de Montaria). Iam à caça de presas pequenas, mas provavelmente só como espectadoras.

${ }^{3}$ As razões pelas quais o fez, a relação entre o ser e o parecer através do traje... tudo isto foi intuído por Paul Claudel (Jeanne d'Arc au Bücher) e admiravelmente revivido na obra "Joana d'Arc na Fogueira" de Arthur Honegger, recentemente levada a cena pelo coro e orquestra Gulbenkian, nos 600 anos do seu nascimento. No plano geoestratégico e mesmo no seu imbricamento com as questões presentes no concílio de Basileia, aguardamos um estudo de Odete Sequeira Martins sobre a intervenção de D. Is abel, duquesa da Borgonha (1397-1471). Sobre as acusações relativas ao traje contidas no Auto de Acusação vd. SACKVILLE-WEST, V. pp. 95s e 281 e PERNOUD, Régine, p. 150.
} 
${ }^{4}$ É mesmo atribuída a Aristóteles durante a Idade Média a obra Secreta Secretorum que elegia Alexandre Magno como o paradigma do perfeito exemplo de governante. Hoje é datado entre os séculos VII-VIII.

${ }^{5} \mathrm{O}$ texto refere o seguinte: «E des pois [de vencer a Batalha de São Mamede] houve batalha em nos campos d'Ourique e venceu-a. E dês ali em diante se chamou el-rei Dom Afonso de Portugal, e entom tomou por armas as cinco quinas». IV Crónica Breve de Santa Cruz. Ed. Fernando V. Peixoto da Fonseca. Lis boa: 1998, p. 113.

${ }^{6}$ Peça raramente referida no contexto da preparação de uma campanha. Vd. Livro dos Conselhos [21] p. 121s.

7 Ordenações Afonsinas, nota de apresentação de Mário Júlio de Almeida COSTA e nota textológica de Eduardo Borges NUNES. 5 Vols., Lisboa: Fundação Calouste Gulbenkian, 1984. Para uma visão geral vd., entre outros, MONTEIRO, João Gouveia. A Guerra em Portugal... pp. 27s; DUARTE, Luís Miguel Duarte. D. Duarte, pp. 70s; VENTURA, Margarida Garcez. D. Duarte, p. 507.

Recebido em abril de 2012.

Aprovado em junho de 2012. 